\title{
Comparative Study on Thyristor and Rectifier Circuit Based DC Motor Control with Improved Power Factor and Total Harmonic Distortion
}

\author{
Salma Nazia Rahman ${ }^{1}$, Tanzina Akter², Mirza Muhammad Yeamin Hossain ${ }^{3}$, \\ Md. Abdullah Al Mahmud ${ }^{4}$ \\ Department of Electrical and Electronic Engineering, University of Asia Pacific, Dhaka, Bangladesh \\ Email address: \\ snazia_1984@yahoo.com (S. N. Rahman), tanzinatrishaa@gmail.com (T. Akter), mhridoy.eee@gmail.com (M. M. Y. Hossain), \\ abdullah-eee@uap-bd.ed (Md. A. Al Mahmud)
}

\section{To cite this article:}

Salma Nazia Rahman, Tanzina Akter, Mirza Muhammad Yeamin Hossain, Md. Abdullah Al Mahmud. Comparative Study on Thyristor and Rectifier Circuit Based DC Motor Control with Improved Power Factor and Total Harmonic Distortion. Science Journal of Circuits, Systems and Signal Processing. Vol. 9, No. 2, 2020, pp. 31-41. doi: 10.11648/j.cssp.20200902.11

Received: March 17, 2020; Accepted: March 31, 2020; Published: August 5, 2020

\begin{abstract}
DC motor is used in many industrial applications. Because it has versatile control characteristics. With the increasing use of power semiconductor units, the speed control of the DC motor is increasingly getting sophisticated and precise. The DC motor can control by various methods, which is as field control, armature voltage control, armature resistance control. The speed of the DC motor is controlled by controlling the armature voltage. Armature voltage is controlled using different single-phase AC/DC converter. Half converter, semi converter, full converter, and dual converter are some of the thyristor-based circuits, which are used for speed control of DC motor. But using power electronics devices causes power factor and total harmonics distortion problem. Different types of Rectifier circuit with filter capacitor is used to reduce the problem of power factor and total harmonics distortion like Conventional single-phase diode rectifier with filter capacitor, single-phase diode rectifier with LC filter, single-phase diode rectifier circuit with series input resonant filter, Single phase diode rectifier circuit with improved parallel input resonant filter. In this paper, we do a comparative analysis of controlling DC motor with improved PF and THD.
\end{abstract}

Keywords: Rectifier Circuit, Converter Drive Circuit, Filter Circuit, Total Harmonic Distortion, Power Factor Improvement, PSIM, MATLAB

\section{Introduction}

DC motors are widely used in the industry. It possesses low cost, less complex control structure and a wide range of speed and torque. There are many methods of speed control of dc drives. They are field control, armature voltage control, and armature resistance control methods. It provides high starting torque, which is required for traction applications. In motor control, we can achieve both below and above the rated speed quite easily. DC motors have some disadvantages that need regular maintenance and it is bulky in size. Generally, the armature voltage control method is widely used to control the dc drives. In the armature control system a controlled rectifier or chopper is used but due involvement of power electronics elements, nonlinear torque speed characteristics are observed which are undesirable for control performance [3].

An electrical drive consists of electrical motors, power controllable and energy transmitting shaft. These electrical drives are used in the industry because of its have low cost, less complex control structure and a wide range of speed. In the modern electrical drive system power electronics converter is used as power controller. Electrical drives are two types: DC drives and AC drives. They are different from each other in this way that the power supply in de drives is given by DC motor and power supply in AC drives given by AC motor. All Standard motors are classified as constant speed and adjustable speed motors. Adjustable speed motors may be operated over a wide speed range by controlling armature voltage and field excitation. The speed below the 
base speed can be controlled by the armature voltage control method and the field control method is used for the above base speed [2]. These motors are customized at the time of installation and it makes them irreplaceable. The armature voltage control method of speed control of dc drive is widely used in which a controlled rectifier is involved. And because of power electronics elements, we observe an undesirable nonlinear torque-speed characteristics [10].

In the past, many researchers worked on various converter topologies of DC motor control for different industrial applications but all of them are thyristor-based. For the simulation of various topologies MATLAB with its toolboxes like Simulink and SimPower System are used [1]. In general, the use of color should be limited to figures only. Text may not be in color, and color shading is never acceptable.

Many researchers worked on various converter topologies of DC motor control for different applications. They used thyristor. In this paper, controlling of a motor by using thyristor is described. This paper also described the use of a filter rectifier circuit to improve the power factor and Total Harmonic Distortion. Different type of rectifier circuit and converter circuit with DC motor is analyzed. For simulation of various topologies, MATLAB with its toolboxes like Simulink and SimPowerSystem and the PSIM software is used.

In the second section, the comparison of the rectifier circuit is described. In the third section, a comparison of different types of filter topologies with rectifier circuits is discussed. In the fourth and fifth section simulation and comparison of a different converter, drive circuit with/without a filter is described respectively.

\section{The Comparison of Rectifier Circuit}

The shape of the input current can be improved by using a combination of input and output filters. In the past, designers have used three passive wave-shaping methods to improve the input power factor and reduce total harmonic distortion THD of conventional ac-to-dc rectifiers. Here, a rectifier circuit with a filter capacitor to improve the input current PF and THD in PSIM is stimulated.

The Rectifier with a filter capacitor circuit is used to improve the PF and THD of input current waveform. Because it is related to the speed control of DC motor. If the input current waveform is more like a sinusoidal waveform it will help to control the speed of a motor, otherwise, it will decrease the performance of the motor. There are different types of rectifiers with a filter capacitor circuit. Among them, four types of rectifiers with a filter capacitor circuit is studied here. A comparative analysis of the four types that gives the best result in terms of PF and THD is given. The four different topologies of the rectifier circuit are [1]: I. Conventional single-phase diode rectifier with filter capacitor. II. Single-phase diode rectifier with an LC filter. III. Single-phase diode rectifier circuit with series input resonant filter. IV. Single-phase diode rectifier circuit with improved parallel input resonant filter. Table 1 shows the specifications of the components used in the topologies.

Table 1. Specification of the components.

\begin{tabular}{ll}
\hline Components & Specifications \\
\hline AC supply & $220 \mathrm{~V} / 50 \mathrm{~Hz}$ \\
Diodes & $\mathrm{DIN} 4936$ \\
Resistances & $100 \Omega$ \\
Capacitors & $60 \mathrm{mF} / 0.1 \mathrm{mF} / 100 \mathrm{mF} / 500 \mu \mathrm{F}$ \\
Inductor & $1 \mathrm{mH} / 50 \mathrm{mH} / 5 \mathrm{mH} / .005 \mathrm{mH}$ \\
\hline
\end{tabular}

A. Simulation result of Conventional single phase diode rectifier with filter capacitor.

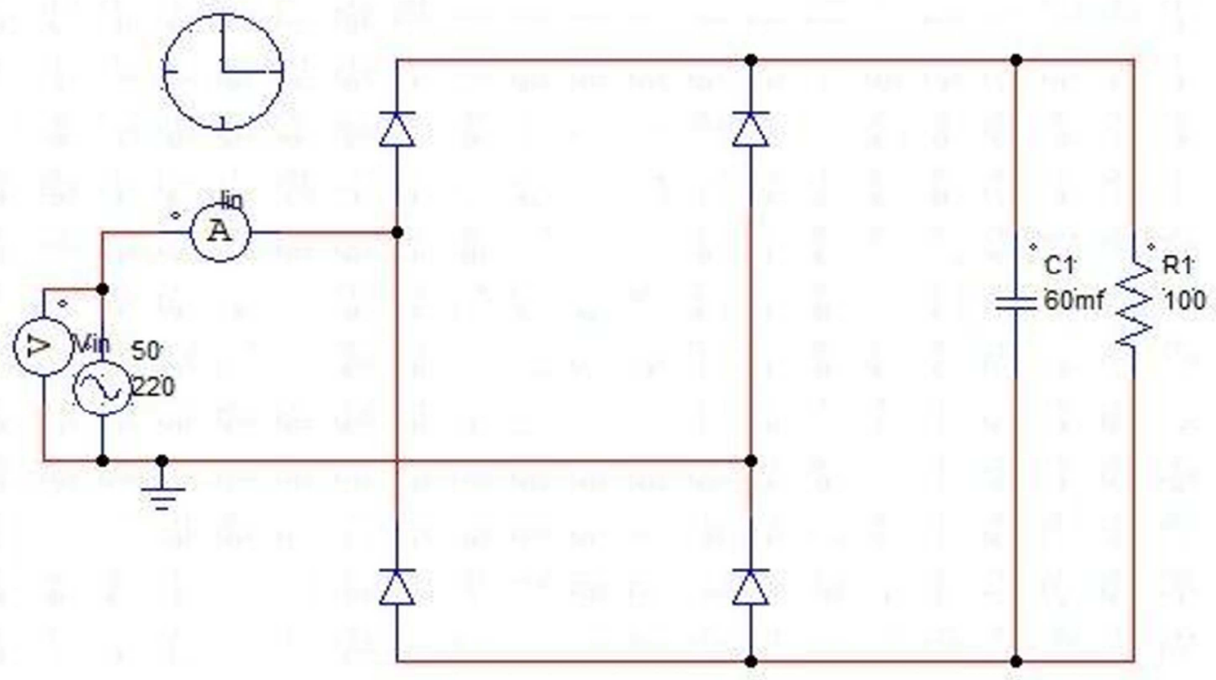

Figure 1. Conventional single-phase diode rectifier with filter capacitor with $C 1=60 \mathrm{mF}$. 


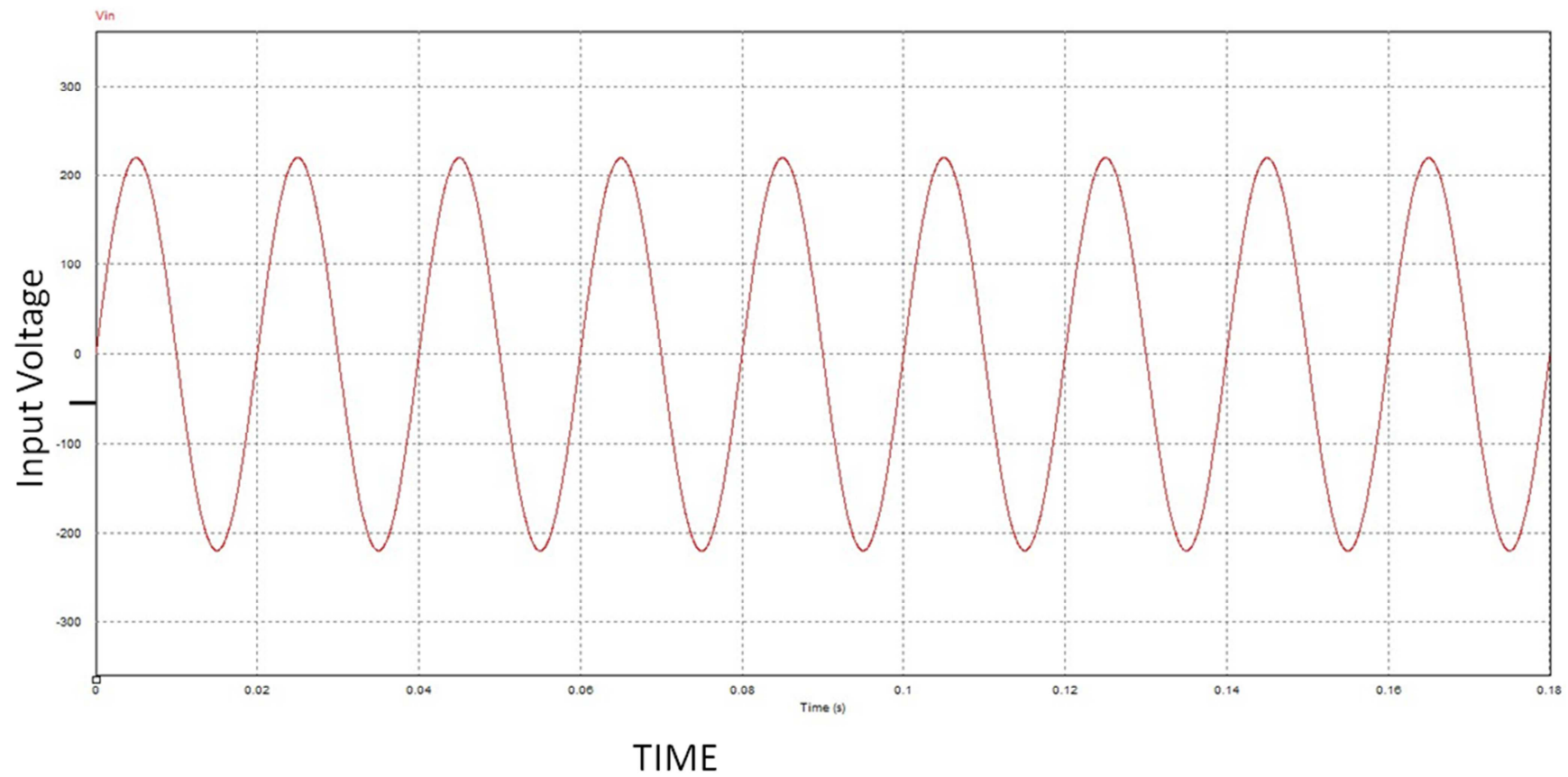

Figure 2. Input Voltage waveform with $C 1=60 \mathrm{mF}$.

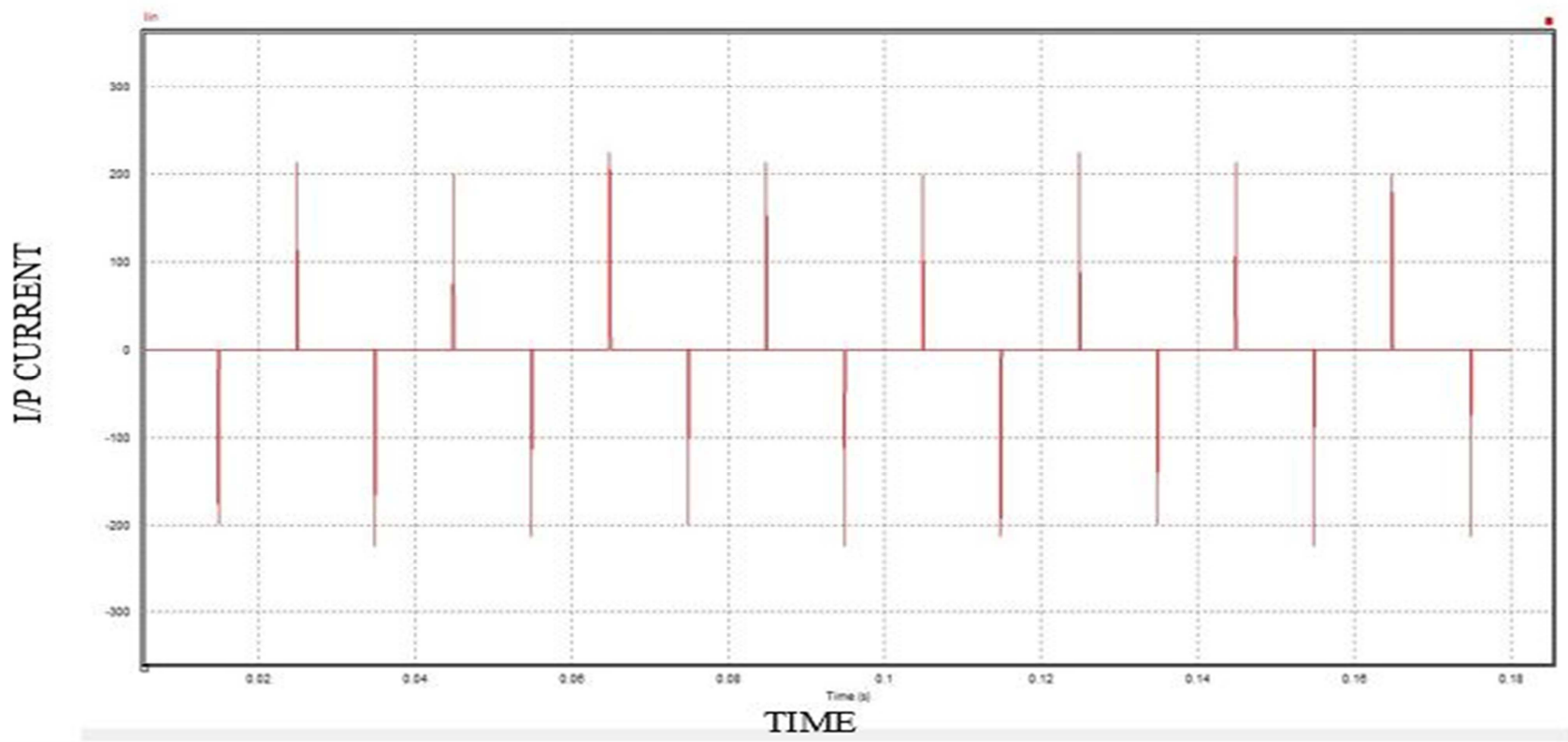

Figure 3. Input Current waveform with $C 1=60 \mathrm{mF}$.

The PF and \%THD of single-phase diode rectifier with different filter capacitor is shown in Table 2.

Table 2. PF and \%THD of single-phase diode rectifier with filter capacitor.

\begin{tabular}{lll}
\hline Capacitors & PF & \%THD \\
\hline $60 \mathrm{mf}$ & 0.17 & 580.4 \\
$0.1 \mathrm{mf}$ & 0.65 & 81.3 \\
$100 \mathrm{mf}$ & 0.14 & 674.6 \\
$500 \mu \mathrm{f}$ & 0.45 & 155 \\
\hline
\end{tabular}

B. Simulation result of Single phase diode rectifier with LC filter 


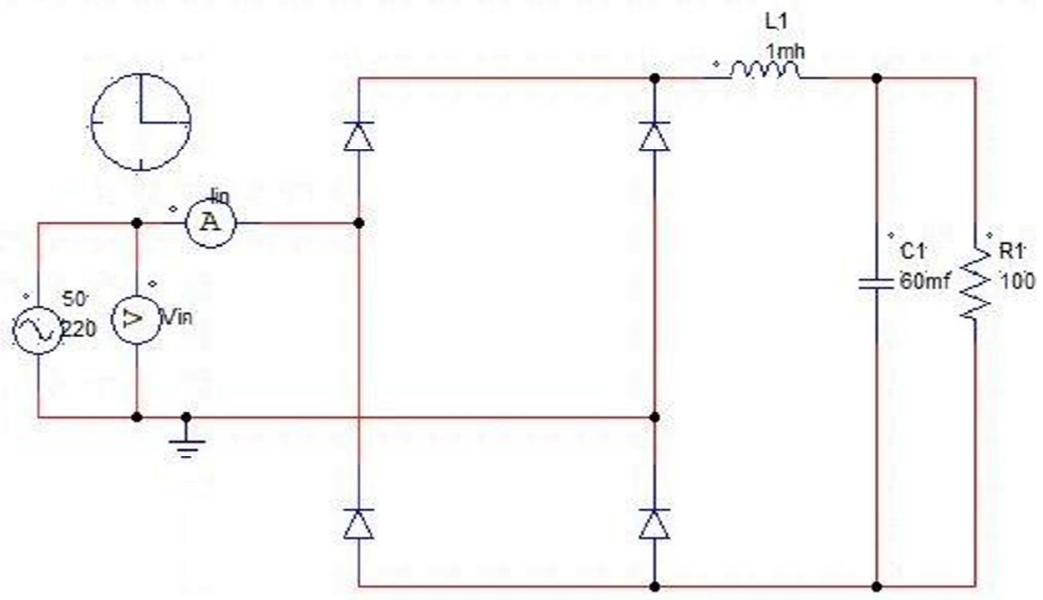

Figure 4. Single-phase diode rectifier with $L C$ filter with $L 1=1 \mathrm{mH}$ and $C 1=60 \mathrm{mF}$.

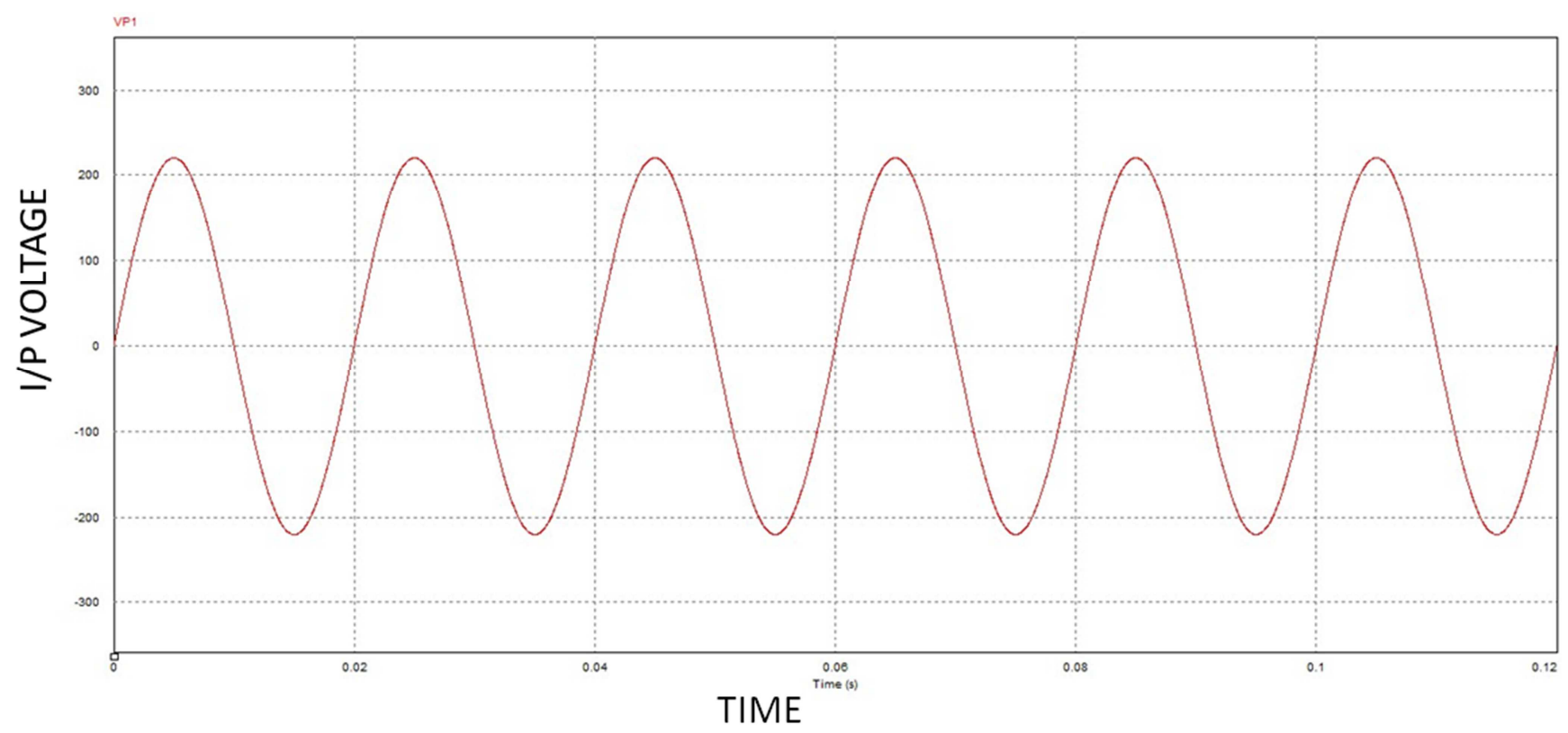

Figure 5. Input Voltage waveform with $L 1=1 \mathrm{mH}$ and $C 1=60 \mathrm{mF}$.

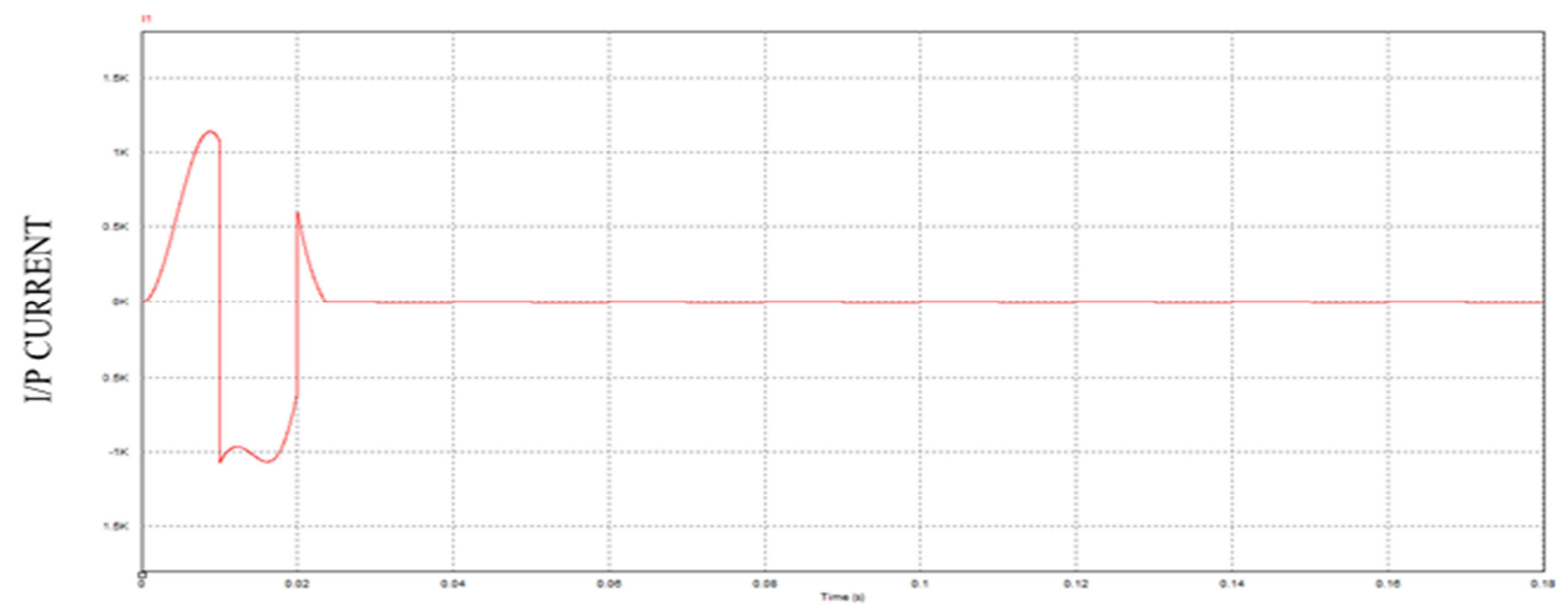

TIME

Figure 6. Input Current waveform with $L 1=1 \mathrm{mH}$ and $C 1=60 \mathrm{mF}$. 
The PF and \%THD of single-phase diode rectifier with different LC filter is shown in Table 3.

Table 3. PF and $\%$ THD of single-phase diode rectifier with LC filter.

\begin{tabular}{lll}
\hline Capacitors & PF & \%THD \\
\hline $60 \mathrm{mf}$ & 0.22 & 481.5 \\
$100 \mathrm{mf}$ & 0.26 & 482.64 \\
$500 \mu \mathrm{f}$ & 0.49 & 132.84 \\
$0.1 \mathrm{mf}$ & 0.56 & 124.23 \\
\hline
\end{tabular}

C. Simulation Result of Single phase diode rectifier circuit with series input resonant filter

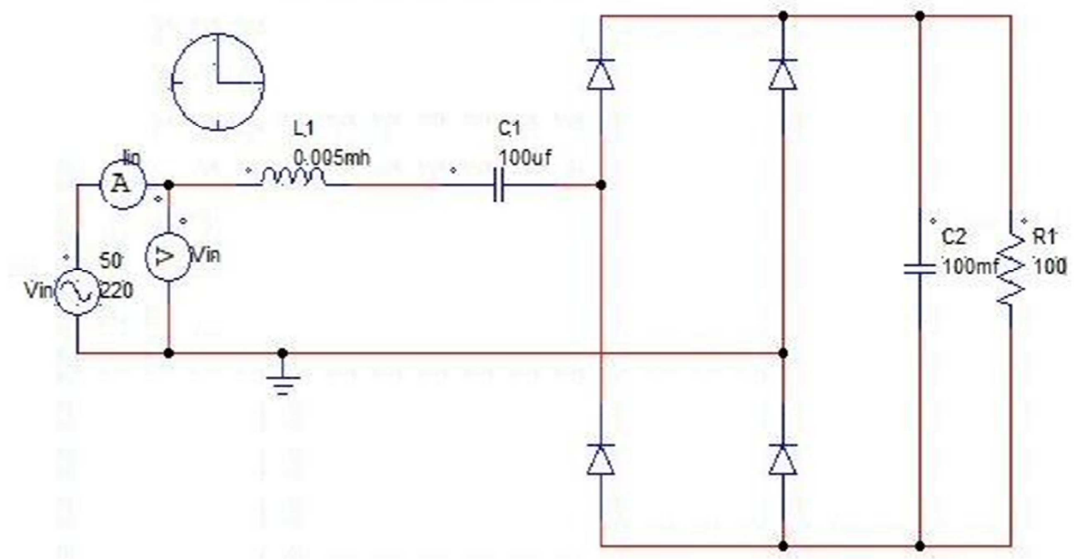

Figure 7. Single-phase diode rectifier circuit with series input resonant filter with $C 2=100 \mathrm{mF}$.

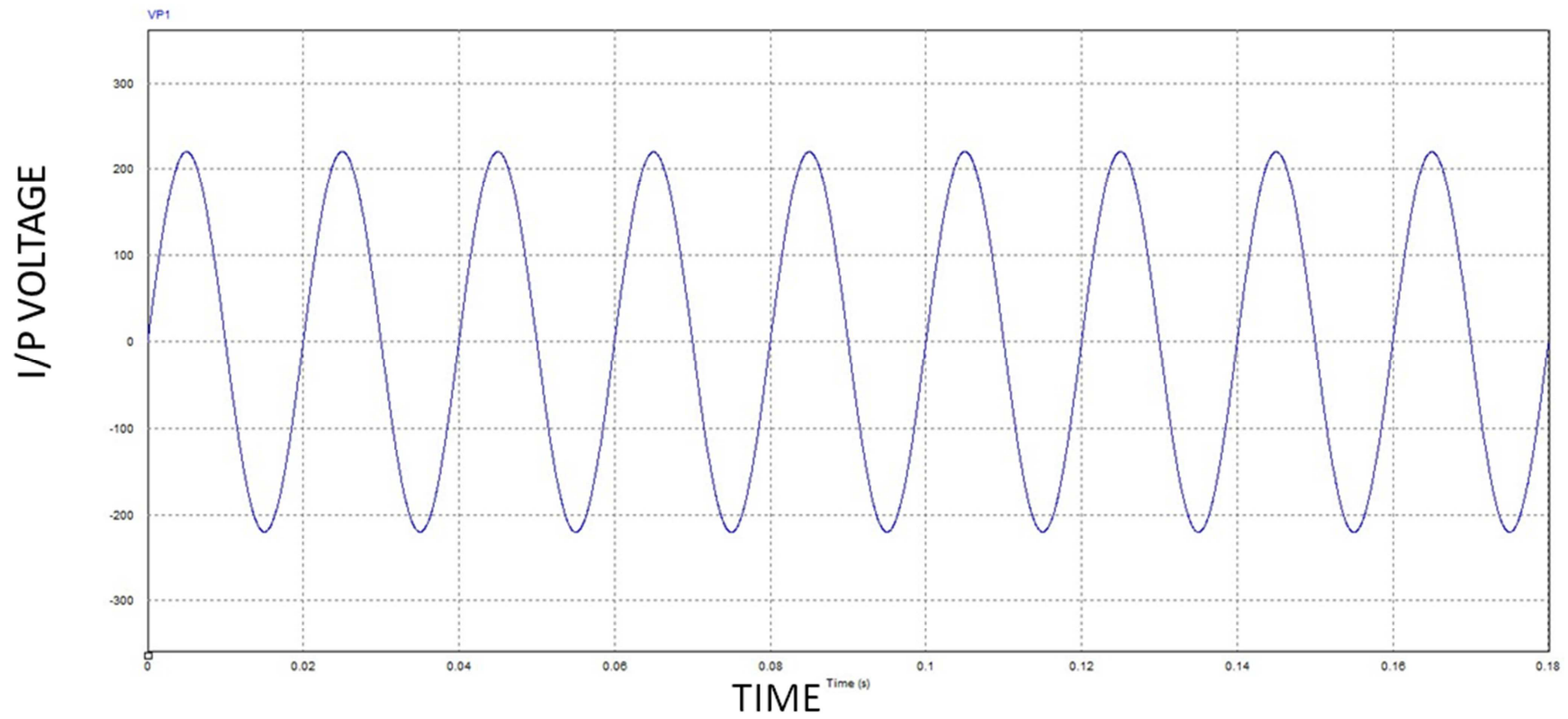

Figure 8. Input voltage waveform with $C 2=100 \mathrm{mF}$.

Table 4. PF and \%THD of single-phase diode rectifier with series input resonant.

\begin{tabular}{lll}
\hline Capacitors & PF & \%THD \\
\hline $100 \mathrm{mf}$ & 0.35 & 39.3 \\
$0.1 \mathrm{mf}$ & 0.47 & 96.4 \\
$500 \mu \mathrm{f}$ & 0.4 & 121.64 \\
$60 \mathrm{mf}$ & 0.54 & 49 \\
\hline
\end{tabular}




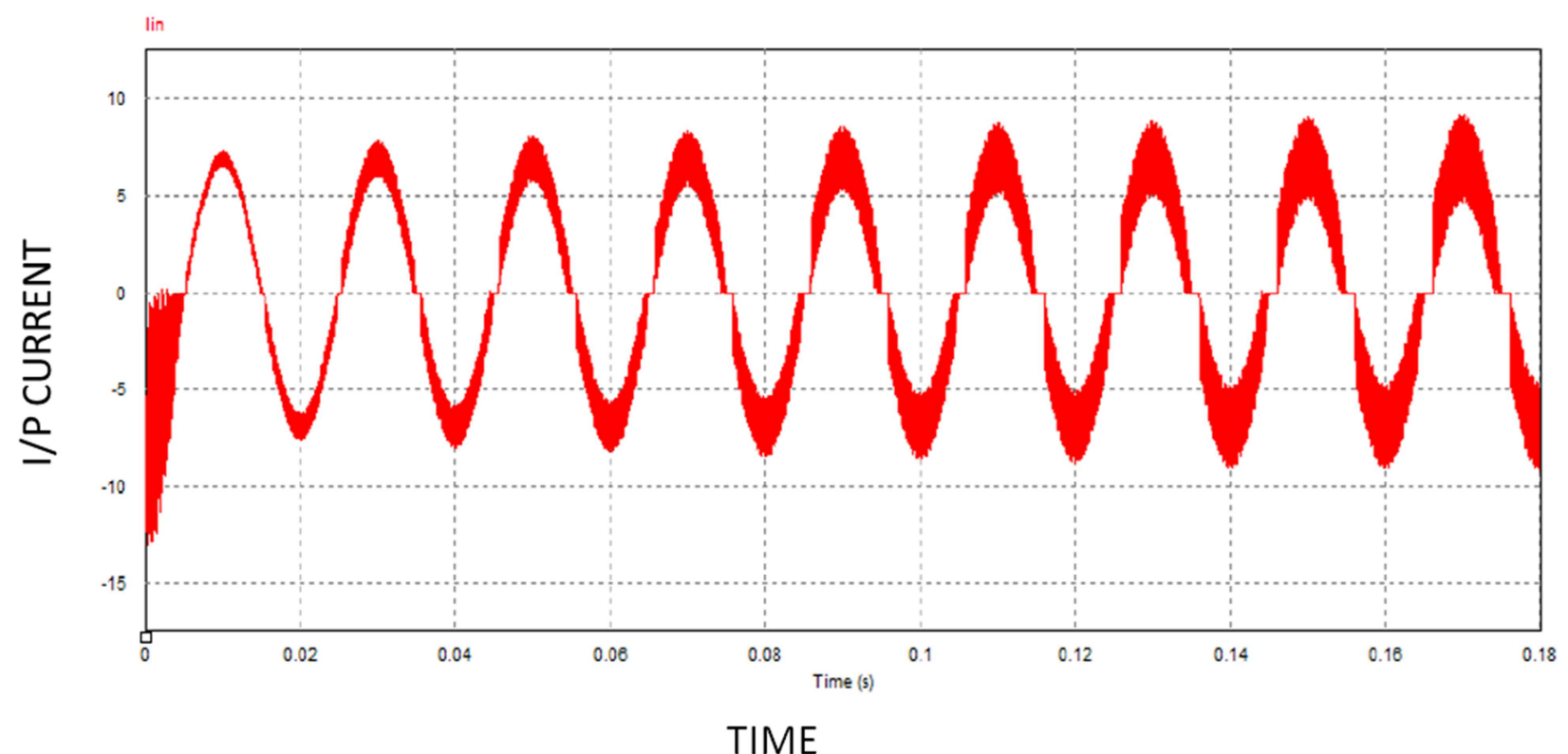

Figure 9. Input Current waveform with $C 2=100 \mathrm{mF}$.

The PF and \%THD of single-phase diode rectifier with series input resonant is shown in Table 4.

D. Simulation Result of Single phase diode rectifier circuit with improved parallel input resonant filter

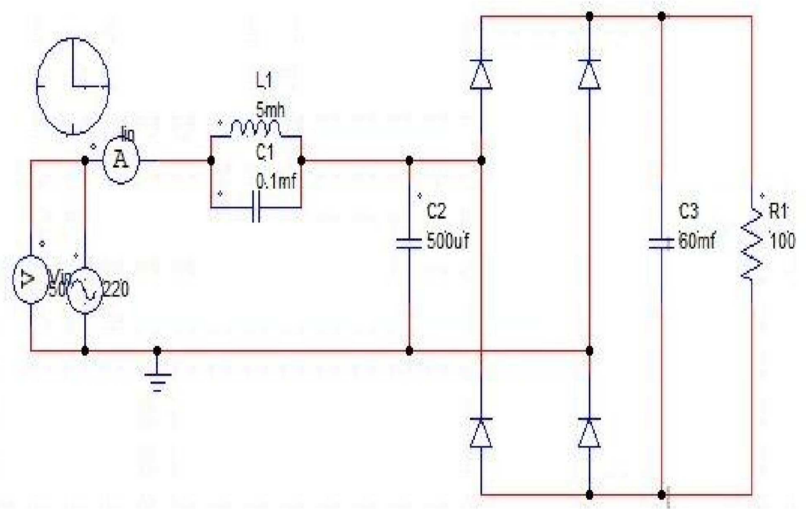

Figure 10. Single-phase diode rectifier circuit with improved parallel input resonant filter with $C 3=60 \mathrm{mF}$.



Figure 11. Input voltage waveform with $C 3=60 \mathrm{mF}$. 




TIME

Figure 12. Input current waveform with $C 3=60 \mathrm{mF}$.

The PF and \%THD of single-phase diode rectifier with improved parallel input resonant filter for different values of capacitors is shown in Table 5.

Table 5. PF and \%THD of single-phase diode rectifier with improved parallel input resonant filter for different values of capacitors.

\begin{tabular}{lll}
\hline Capacitors & PF & \%THD \\
\hline $60 \mathrm{mf}$ & 0.84 & 10.21 \\
$100 \mathrm{mf}$ & 0.64 & 12.04 \\
$0.1 \mathrm{mf}$ & 0.66 & 22.78 \\
$500 \mu \mathrm{f}$ & 0.19 & 15.26 \\
\hline
\end{tabular}

Table 6. Parameters for various filter topologies.

\begin{tabular}{lll}
\hline Type of Filter /Parameters & PF & \%THD \\
\hline Single phase diode rectifier with filter capacitor & 0.65 & 81.3 \\
Single phase diode rectifier with LC filter & 0.56 & 124.23 \\
Single phase diode rectifier with series input resonant filter & 0.54 & 49 \\
Single phase diode rectifier with improved parallel input resonant filter & 0.84 & 10.21 \\
\hline
\end{tabular}

\section{Comparison of Different Types of Filter Topologies with Rectifier Circuit}

Here different types of filter topologies with rectifier circuit to improve the input current PF and THD is stimulated. Improved value after simulating all of the filter circuits is given in Table 6. Improved value is measured from the filter capacitor when the capacitor value is $0.1 \mathrm{mF}$, from LC filter when the capacitor value is $0.1 \mathrm{mF}$, from series input resonant filter when capacitor value is $60 \mathrm{mF}$, from improved parallel input resonant filter when the capacitor value is
$60 \mathrm{mF}$.

\section{Simulation Result of Converter Drive Circuit}

There are many methods to control the speed of DC motor. Converter drive with thyristor is one of the methods to control the speed of a motor. There are four types of converter drive circuits. After doing the simulation of these four types of circuits in SIMULINK, the result is studied. Moreover, from the result it is found that the THD of the converter drive circuit is improved when we use a rectifier 
circuit with a filter, which helps to control the speed of the motor more efficiently.

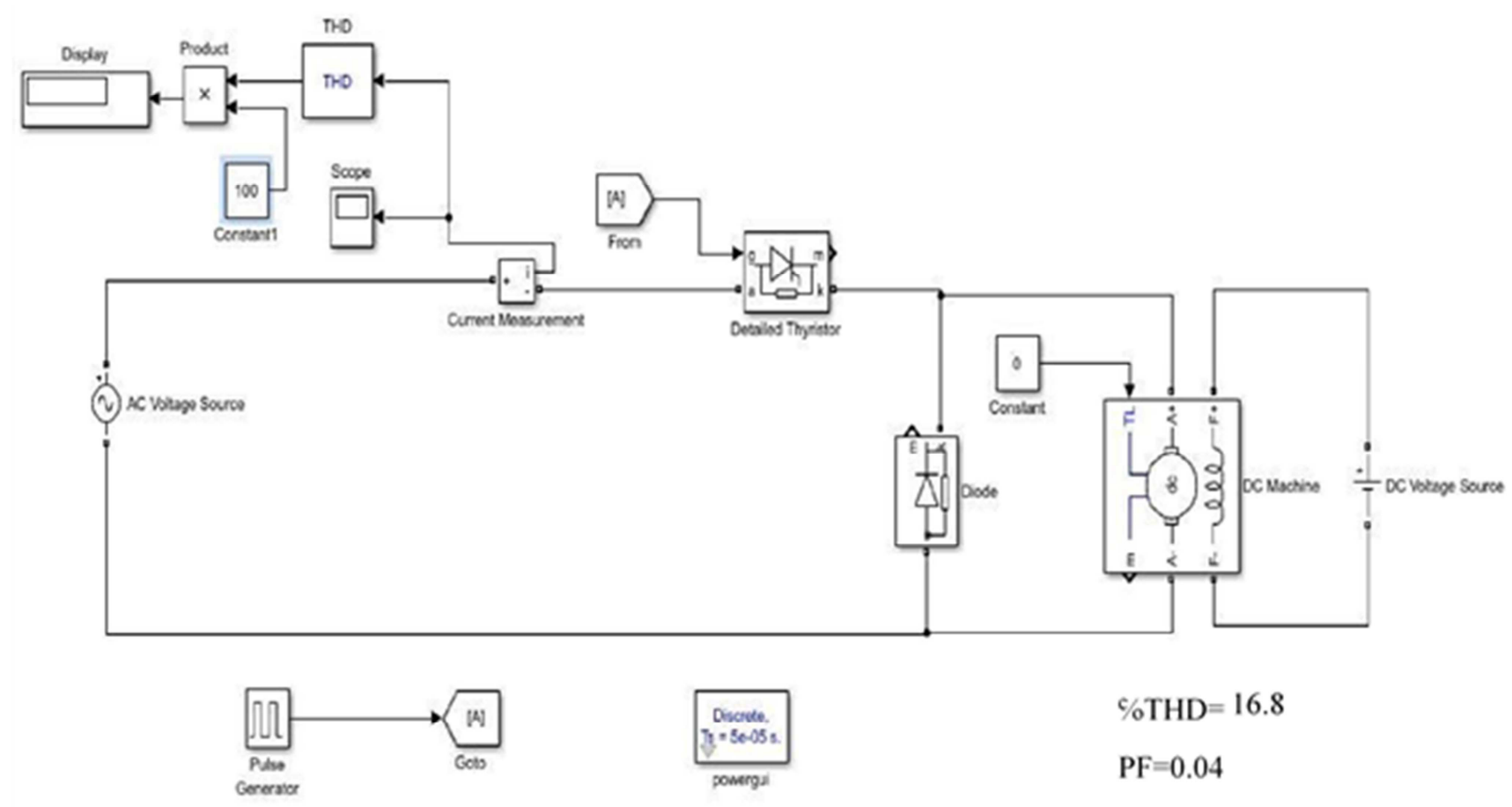

Figure 13. Half wave converter drives without filter circuit.

For Half wave converter drives without filter circuit, the \%THD and PF value is 16.8 and 0.04 respectively

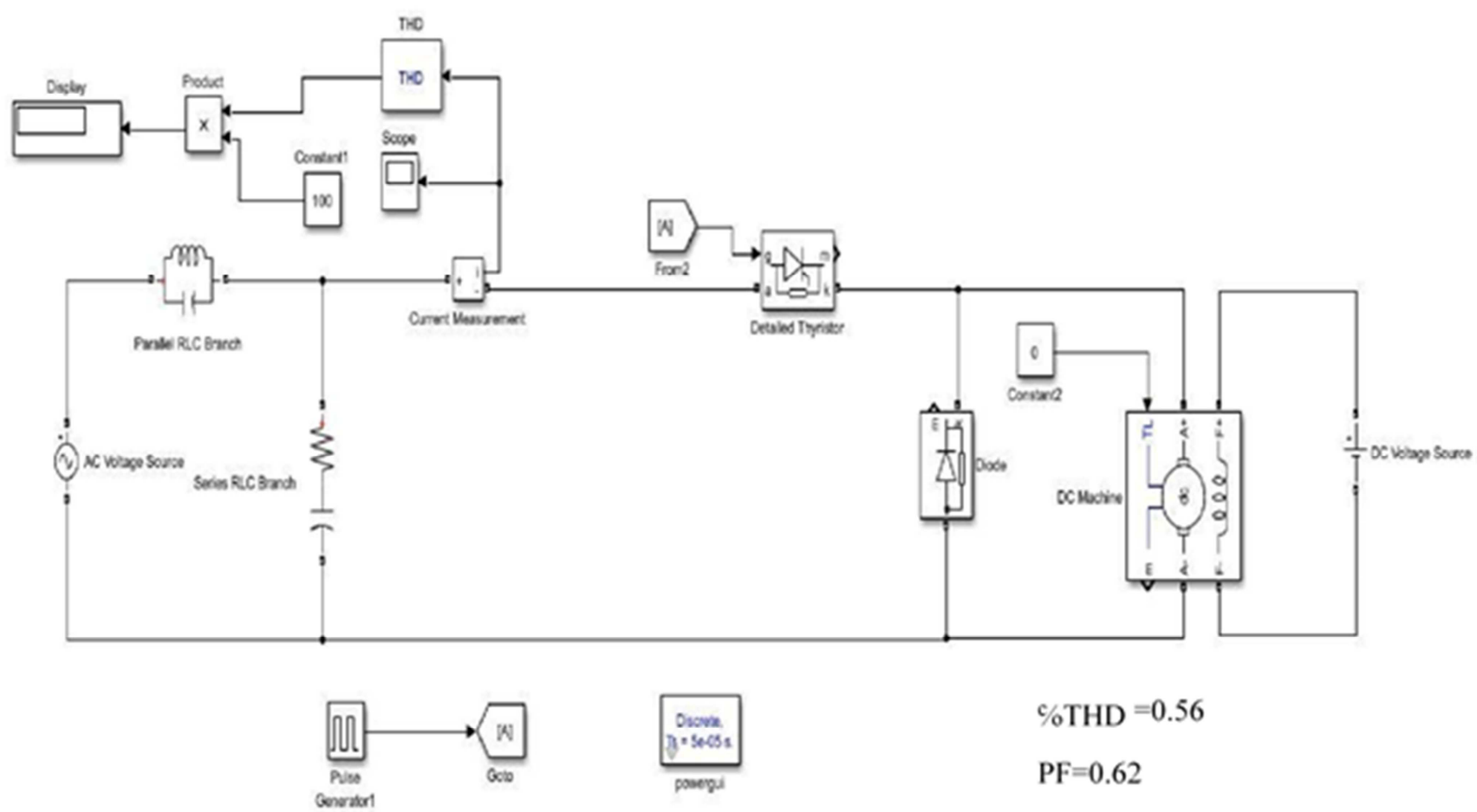

Figure 14. Half wave converter drives with filter circuit.

For Half wave converter drives with filter circuit, the \%THD and PF is 0.56 and 0.62 respectively. 


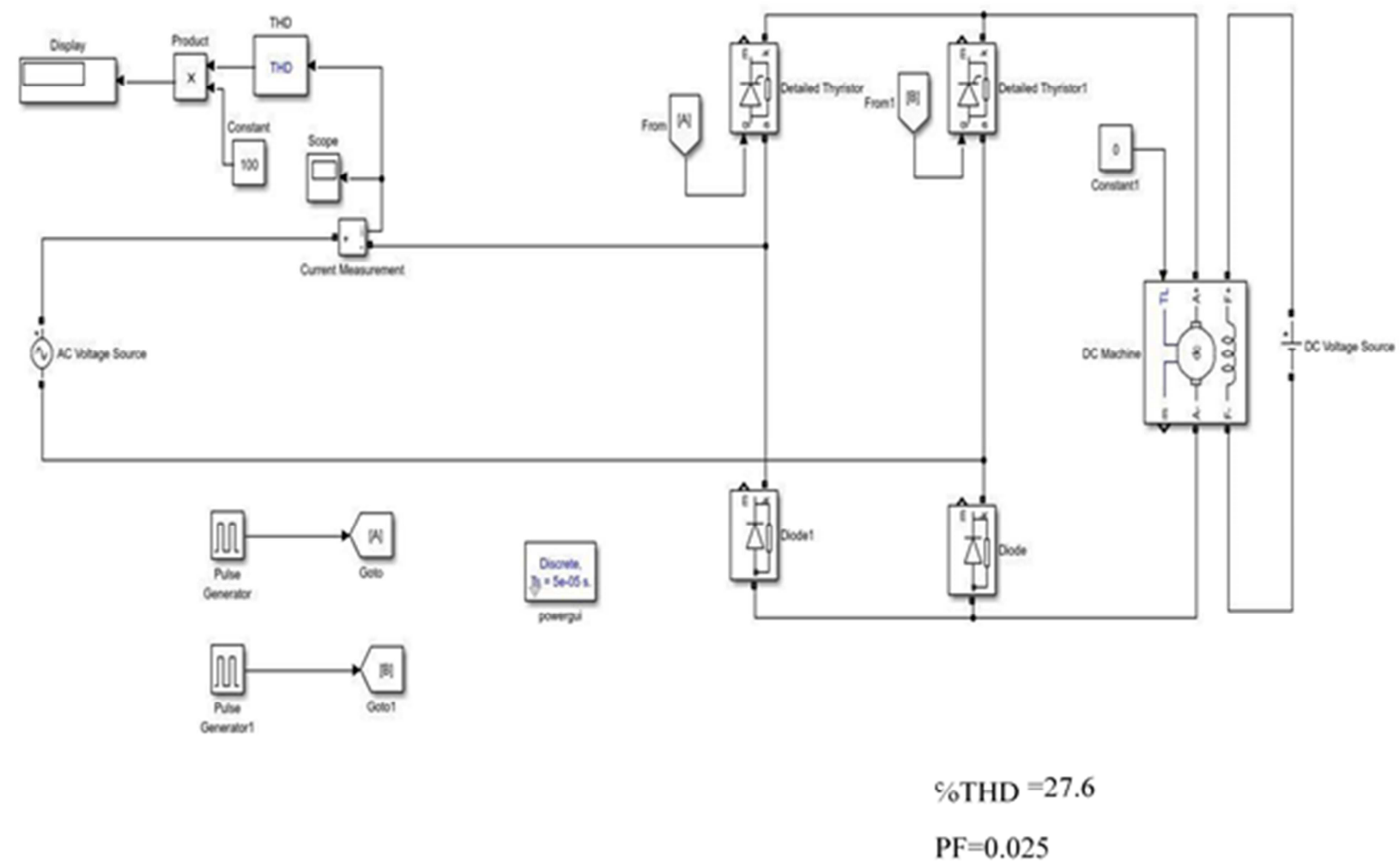

Figure 15. Semi converter drives without filter circuit.

For Semi converter drives without filter circuit, the \%THD and PF is 27.6 and 0.025 respectively.

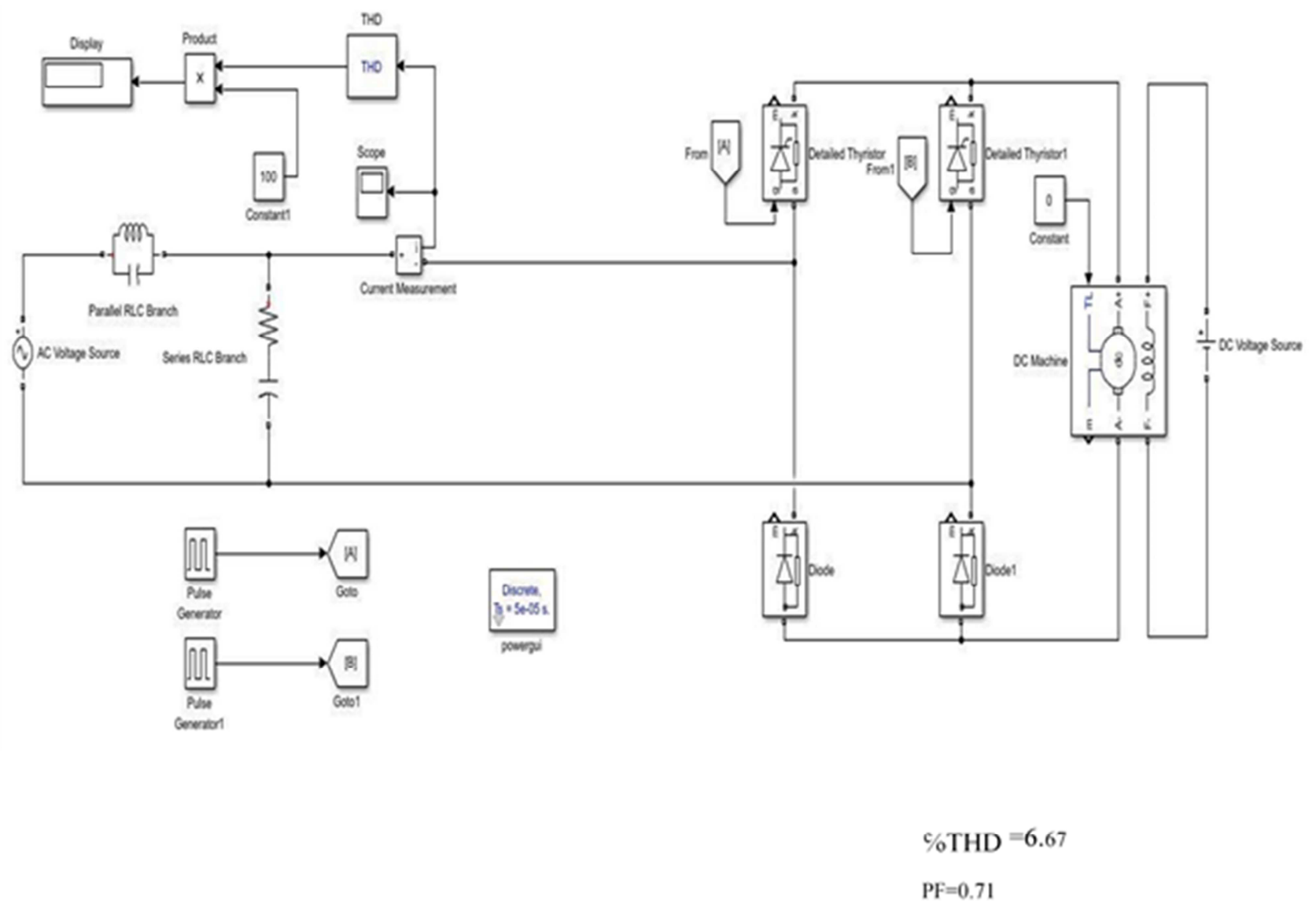

Figure 16. Semi converter drives with filter circuit. 
For Semi converter drives with filter circuit, the \%THD and PF is 6.67 and 0.71 respectively.

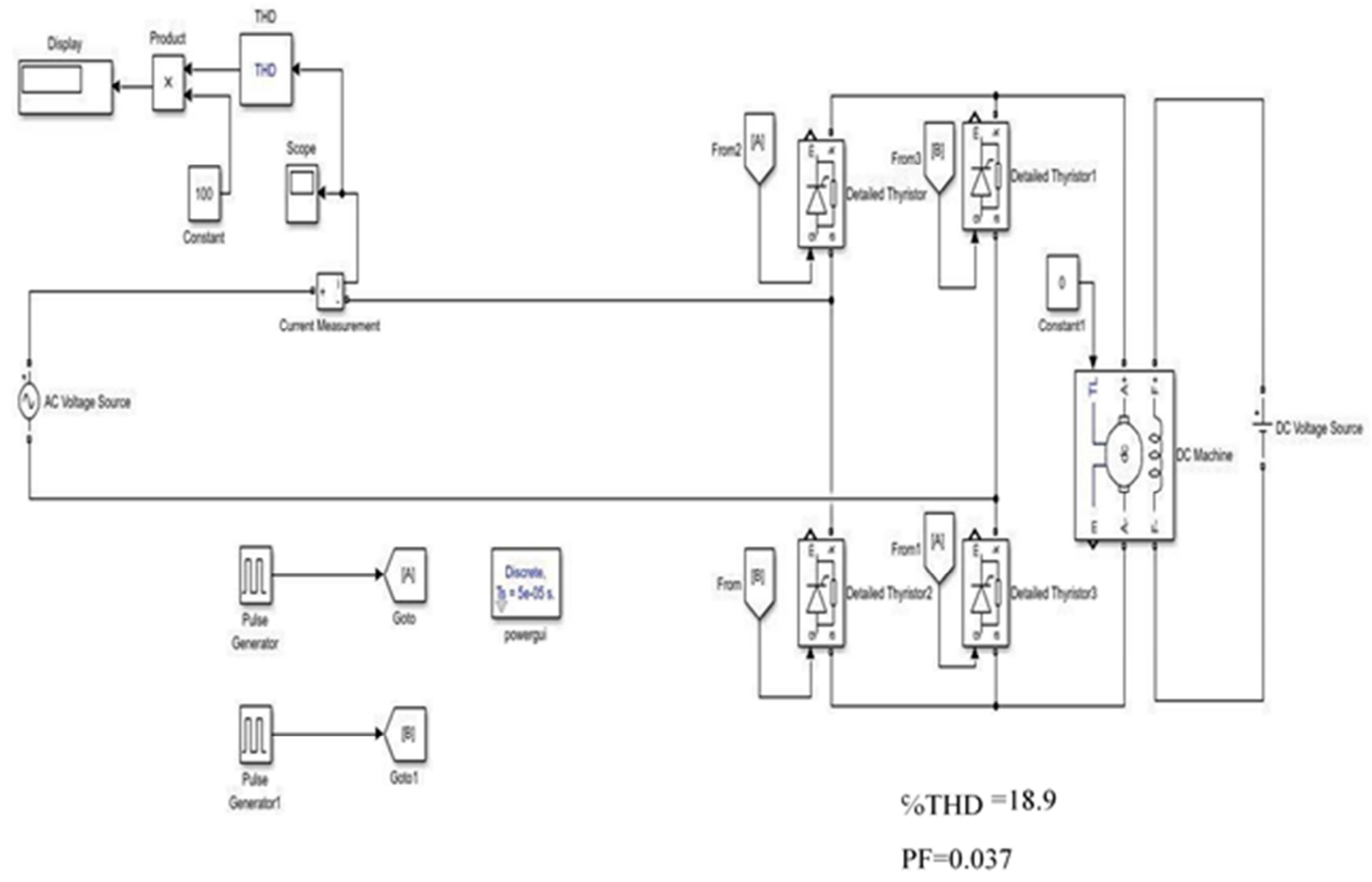

Figure 17. Full converter drives without filter circuit.

For Full converter drives without filter circuit, the $\%$ THD and PF is 18.9 and 0.037 respectively.

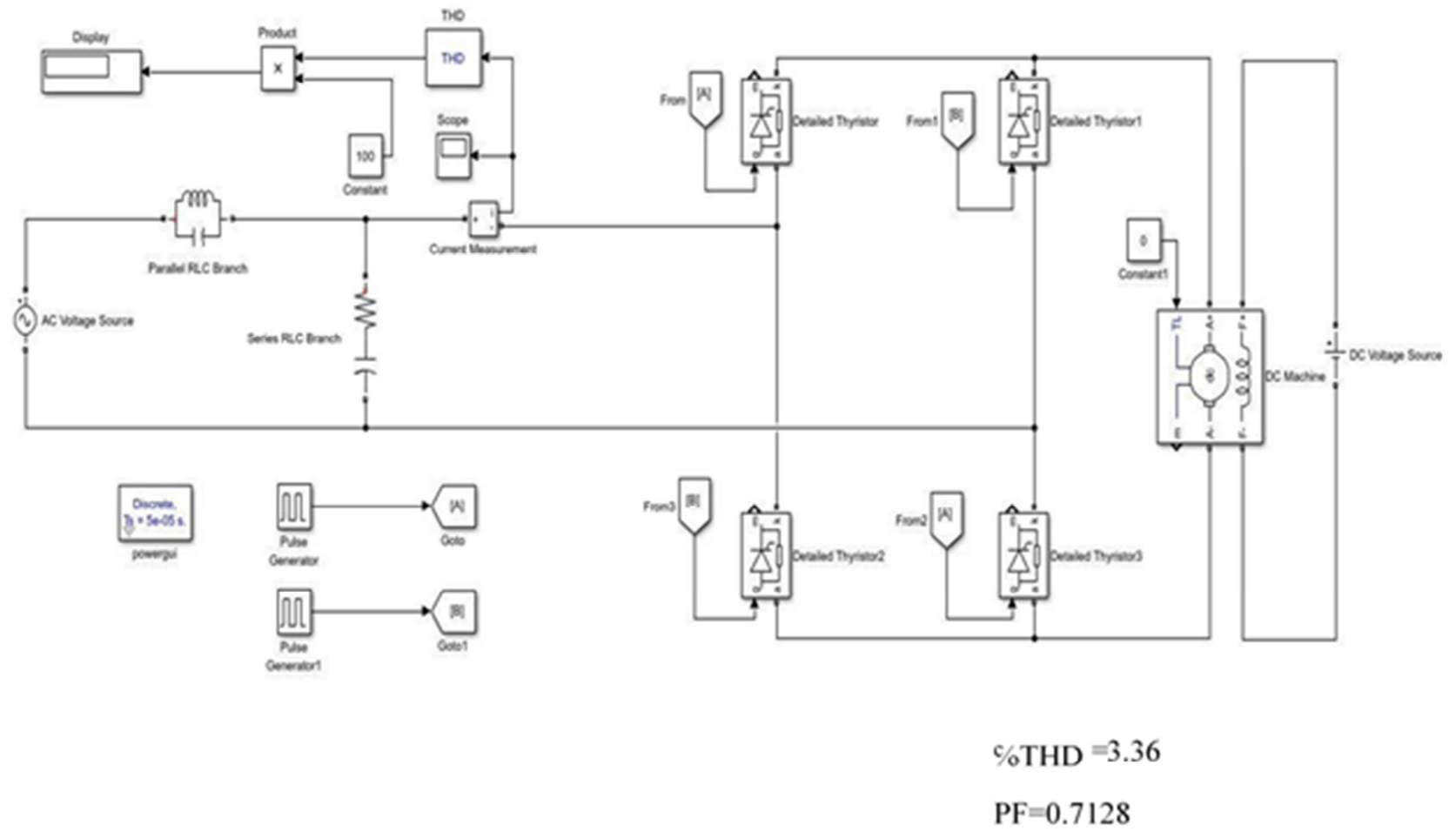

Figure 18. Full converter drives with filter circuit. 
For Full converter drives with filter circuit, the \%THD and $\mathrm{PF}$ is 3.36 and 0.7128 respectively.

\section{Comparison of DC Drives with and Without Filter Circuit}

Four types of DC drives, half-wave converter drive, semi converter drive, full-wave converter drive and dual converter drive is used and also simulated in SIMULINK to observe the improvement. After the simulation, we get THD and PF value of these four types of circuit. Comparison of \%THD for different drives and comparison of PF for different drives are given below. Table 7 shows the value of total harmonic distortion with improved total harmonic distortion for different type of converter drives at firing angle $89^{\circ}$ and Table 8 shows the value of power factor with improved power factor for a different type of converter drives at firing angle $89^{\circ}$.

Table 7. Comparison of $\%$ THD for different drives.

\begin{tabular}{lll}
\hline Type of drive & Without filter circuit \%THD & With filter circuit \%THD \\
\hline Half wave converter drive & 16.8 & 0.56 \\
Semi converter drive & 27.6 & 6.67 \\
Full wave converter drive & 18.9 & 3.36 \\
Dual converter drive & 25 & 4.56 \\
\hline
\end{tabular}

Table 8. Comparison of $P F$ for different drives.

\begin{tabular}{lll}
\hline Type of drive & PF without filter circuit & PF with filter circuit \\
\hline Half wave converter drive & 0.04 & 0.62 \\
Semi converter drive & 0.025 & 0.71 \\
Full wave converter drive & 0.037 & 0.713 \\
Dual converter drive & 0.028 & 0.73 \\
\hline
\end{tabular}

\section{Conclusion}

In this paper, four types of power factor improvement topologies are implemented and their performance is compared on the basis of five parameters those are power factor, input current distortion factor, input current harmonic factor, input displacement factor and total harmonic distortion. And it is found that the single-phase diode rectifier circuit with improved parallel input resonant filter performs well. Then the same parallel input resonant filter is applied with different types of DC drives systems which are single phase half wave converter drive, single phase semi converter drive, single phase full converter drive and single phase dual converter drive. A significant improvement in power factor and total harmonic distortion is observed. But the selection of filter components still involves complex mathematical calculations, so the selection of components can be done by applying artificial intelligence.

\section{References}

[1] Rohit Gupta and Ruchika "Thyristor based DC motor control with improved PF and THD" International Journal on Electrical Engineering and Informatics - Volume 5, Number 4, December 2013.

[2] Ankita Ringe, Ragini Sonbarse and Prof. Apurva Bhalerao "Study On Speed Control of DC MOTOR Using Thyristor" Volume: 04 Issue: 02 | Feb -2017.

[3] Rohit Gupta, Ruchika Lamba and Subhransu Padhee "Thyristor Based Speed Control Techniques of DC Motor: A
Comparative Analysis" International Journal of Scientific and Research Publications, Volume 2, Issue 6, June 2012.

[4] Muhammad H. Rashid "Power Electronics Circuits, Devices, and Applications" Third Edition.

[5] B. L Theraja and A. K Theraja "A Textbook of Electrical Technology, Volume II"

[6] Jump up http://www.electrical-engineeringassignment.com/voltage-control

[7] B. L Theraja and A. K Theraja "A Textbook of Electrical Technology, Volume I"

[8] S. J. Chapman, Electric Machinery Fundamentals, New York: WCB/McGraw-Hill, 1998.

[9] N. Mohan, Electric Drives: An integrative approach, University of Minnesota Printing services, 2000.

[10] D. A. staton, M. I. McGilp and T. J. E. Miller, "DC machine teaching experiment," in proceedings of the European Power Electronics Association EPE, Brighton, pp. 35 - 40, 1993

[11] M. Nedeljkovic and Z. Stojiljkovic, "Fast current control for thyristor rectifiers," IEE Proceedings- Electr. Power Appl., Vol. 150, No. 6, pp. 636- 638, Nov. 2003.

[12] $\mathrm{H}$ ong Liang, Yuanyuan $\mathrm{Pu}$, Jie Liang, Signals and Linear System Analysis-Method and Realization Based on MATLAB, Higher Education Press, China: Beijing, 2006.

[13] P. S. Bhimbhra, Power Electronic, Khanna publishers, 2010.

[14] Wai Phyo Anug, "Analysis on Modeling and Simulink of DC Motor and its Driving System Used for Wheeled Mobile Robot," World Academy of Science, Engineering and Technology 32, pp. 299-306, 2007. 